\title{
Study on the Aesthetic Value and Folk Culture of Lanling Xiaoguo Clay Sculpture
}

\author{
Yanqing Hou $^{1, a}$ \\ ${ }^{1}$ Feixian School, Linyi University, Feixian, Shandong, P.R.China \\ alydxmfl@126.com
}

\begin{abstract}
As a form of folk art, Xiaoguo clay sculpture has its unique artistic value and cultural value, which have played an important role in the aspects of displaying in regional aesthetic features and cultural heritage.
\end{abstract}

Keywords: Xiaoguo Clay Sculpture, Artistic Value, Cultural Value

\section{Introduction}

Fork arts from different times, nationalities and regions have their own characteristics and styles, which are shaped by different origins, purpose, craft and materials. While the colors and styles in Chinese folk arts have their own distinguished aesthetic features. Maintaining in a relatively independent and stable profile in thousand years, Chinese fork arts are loaded with folk spirits through their content, forms, styles and aesthetic standards. In the process of clay sculpture, Lianling Xiaoguo clay sculpture is famous for it's exaggeration shapes, beautiful colors and unique styles. Meanwhile, it's original place in the village of Xingming, Lanling county, Linyi, Shandong Province has been named as "Chinese Folk Arts (Clay Sculpture) Village" by China Ministry of Culture.

\section{Historical Origins}

According to the research, Xiaoguo Clay Sculpture originated from middle of Qing Dynasty. The record in Cangshan Chorgraphy said: The represent place of Cangshan clay toys is Xiaoguo Village. The art of Xiaoguo clay sculpture originated from the reign of Xianfeng, Qing Dynasty (1851-1861) and the originator of Xiaoguo clay sculpture is the late clay artist Li Xianzhi's grandfather Li Zongbiao, who had learnt the sculpture skill from Tianjin. In order to make a living, he sculpted the mud into human shape as well as the livestock with the process of drying, coating and coloring, then sold them in market."

The origin and formation period of Xiaoguo clay sculpture is in the middle and late stage of Qing Dynasty. From late Qing Dynasty till the early China, this art has reached to it's rapid development and peak point. During this period, it has started to regional spread and inheritance, which urged to spring up a large number of clay artistes with classic skills. Furthermore the clay sculpture market has accordingly developed to south Shandong, north Jiangsu and Hebei province. However, at the early China, Xiaoguo Clay Sculpture has fell into the low tide. Since 1980s, with the acceleration development of reform and opening up of China, the culture ecology in the original frame of agriculture civilization has rapidly collapsed and the market has slumped. The situation has almost put Xiaoguo Clay Sculpture, the folk art in tradition of more than a hundred years, into extinction[1]. Until recent years, the artistic value and culture value of Xiaoguo clay sculpture have been re-valued and affirmed. In 2006, it has been loaded into The First Batch of Provincial Intangible Cultural Heritage in Shandong Province by the government.

\section{Technological Features}

The technological procedure of Xiaoguo Clay Sculpture is mainly divided into four parts: molding, kneading, shaping and coloring. Actually, the practical procedure of clay sculpture is far more complex than what has been described literally. It has been shaped up nearly with 15 steps, which are molding, soaking, kneading, casting, installing whistle, coating, coloring, etc[2].

3.1. Style Characteristics: Distinctive sound toys, which has been called as "Xiang Huo" by local people. It is because that majority of Xiaoguo Clay Sculpture can make the sound, which has driven the attention from the children. Artists rise the sound in two ways: one is to divide the sculpture into two parts, and install the reed whistle at the juncture. Then they seal the juncture by kraft paper, when they pull the paper, the sound will come out. Another way is hollowing inside the sculpture and install the clay whistle in the bottom, then open one or more stomata in the back of sculpture. When they blow in the stomata, the sound will come out. It is that the artists skillfully combined the 'sculpture', "sound" and "color" together, which made the clay toys vivid and welcomed by the folks.

3.2. Molding Characteristics: Most Lanling clay sculpture have only a major viewing surface, this is also the biggest distinction from the sculpture in other regions around China. The shapes and colors are all loaded in the front of Xiaoguo 
clay sculpture, while artists always keep the back with its own clay body. This also assured the stable of the sculpture and it seems like been squashed from the side view. This empaistic and complanate physical characteristics also formed a unique feature of the sculpture. Clay sculpture has strong plasticity, while also has it's limitation such as poor stability, easily broken and lack of portability. However, Xiaoguo artists has cleverly overcome this "limitation", they compressed the body proportion and stretched the clay figurines to crosswise, which made the clay shape more exaggeration and also avoided its feature of easily broken. Due to this cleverly "compression" and "simplify", the clay sculpture is much more lively and vivid.

3.3. Coloring Characteristics: Xiaoguo clay sculpture is mainly coloring by 5 colors, and combines with painting. The common ground of clay sculpture from Xiaoguo, Shaanxi Fengxiang, Hebei Yutian, Henan Huaiyang is that the painting played an important role in sculpture, then the molding. While the different point is in the painting process of Xiaoguo sculpture, which only use 5 colors of white, black, red, green and yellow. This is why Xiaoguo clay sculpture is distinguished from other sculpture to the great extent. This "5 colors" idea is formed due to the limitation of production and life style, also is the achievement of optimized designing style. It is also based on the special requirement of customers and visitors, Xiaoguo artists has greatly streamlined the process, which is not only focus on the professional skills but also on the artistic style. For the choice of colors, they only use the bright and eye-catching colors and abandoned all unnecessary ones[3]. In conclusion, Xiaoguo clay sculpture has its own discipline in use of color and color matching, it is also the way that composed it's apparent decoration features.

\section{Aesthetic Value}

The core value of Xiaoguo Clay Sculpture is aesthetic value, on the one hand it brings people the joy of beauty, on the other hand it increases the pleasure of life.

4.1. Originality: Firstly, it means the original craft skills. The most obvious feature Xiaoguo clay sculpture has is that almost all of the sculptures are made according to the modules with original craft skills. Furthermore, the painting material used in the process is grinded by a kind of white stone. And the other color such as red, green and yellow is in used of traditional colors, which deeply reflected with the traditional local folk custom. Secondly, it means the original inheritance way, which basically in a family tradition-base. Thirdly, it means the origin of the clay sculpture. The older artists always saying that the clay toys are made for children, as long as it looks fancy, they do not care if the shape is really in similar with the human or livestock. There's no standard on making clay toys other than the artists' hand and mind. They just knead the clay in whatever they like them to be. The artists do not follow a fixed form to knead the sculpture, they just follow their own aesthetic point of view.

4.2. Freehand brushwork in the clay sculpture. The most apparent feature in Chinese artworks is freehand, which also reflected in Xiaoguo clay sculpture in direct. It does not pursue to be similar in form or appearance, but in spirit. The empaistic and complanate physical characteristics appeared in Xiaoguo clay sculpture is not limited by the skills, forms or appearance, so as in the process of painting. They applied a serious of painting skills such as wiping, depicting, sketching, painting, etc. This streamlined process is the most straightforward description of life. Although the clay sculpture is made with the traditional materials and method, it dose not effect the degree of its artistic value.

4.3. Symbolization: the nature of human beings is to survive and reproduction. The awareness of living is the basic cultural consciousness, as well as the basic cultural connotation in the art of folk clay sculpture. In facts, the awareness of reproduction is also life consciousness and the reproduction is the continuation of life, just as the symbolization in Xiaoguo clay sculpture[4]. In Chinese tradition, the symbols of plenty of progeny are always the objects like peach, lotus seeds, pomegranate, frog and fish; the symbols of rebirth are tiger, cat, lion, dog, cattle and sheep; and the kinds of clay sculptures are also given the hope of good luck and pray. Generally, in the molding idea of folk art, the objects in real world seems to associated with a particular meaning, also with the people's production and life practice.

The tone in folk art is to be happy, and the praise is to be in high spirits and energy. Consisting with the simplest material-mud, and the simplest tool-hands, Xiaoguo clay sculpture has created the vigorous and lifelike figure, livestock, plant even the kinds of immortal and ghost. This is a truly celebration of life and the pursuit of better compliment.

\section{Cultural Value}

The major themes of Xiaoguo clay sculpture are included in the follow types:

5.1. The statue of god or the Buddha: mainly in express of people's beliefs and the whishes of good luck, peace and happiness and drive away any lurking evil air. Such as the statue of Maitreya Buddha, the Goddess of Guanyin, Arhat, Singzi Niangniang, the God of Wealth, the God of Longevity, Nuwa, Zhong Kui (the ghost buster), etc.

5.2. Opera Characters: mainly in express of the admiration of the heroes or the pure love in the world, with a lot of historical figures and stories, such as Yang Zongbao and $\mathrm{Mu}$ 
Guiying, Liang Shanbo and Zhu Yingtai, Niu Lang and Zhi Nv, Yue Fei, Guan Gong, Zhang Fei, Zhu Geliang, Li Bai, etc. All the sculptures of these people are influenced by their characteristics, and the kneading of them are following the rule of pursue to be similar in spirit. Artists are adept to grasp the most salient and representative opera plot and character features. They knead the sculpture in combination with their own characteristics, which make the figures vivid and energetic.

5.3. Beautiful Women, Children: mainly in express with the hope of health and better life. Such as the statue of the child who hold the fish or peach and the child who hold the gold ingot, etc. The figures of these statues are always the kind of chubby children with the exaggeration with their big head. They look like full of innocence.

5.4. Animals: mainly in express with the pray for flourish and happiness in the family. Such as tiger, the pair of lions, monkey, chicken, dog, cattle, sheep, rabbit, frog, etc. While when in kneading the animals such as cattle, horse and tiger, the artists always highlight the shape, expression, strong and steady features of the statues. "Shape" represents the most outstanding feature of the animals; the artists will exaggerate the shape of them. In artists' point of view, animals are lovely, strong, beautiful with coexist of childlike and mighty. "Expression" shows in animals facial feature, with wrinkled brow and big eyes. Tigers and lions should be ferocious, cattle and horses should be loyal and tame. "Strong" means to build the statue with healthy and stocky body. "Steady" is to show act steady in moving, the foot grip firmly into the ground.

5.5. Fruits: mainly with the hope of the bumper harvest, plenty of children. It is so important for color matching; it should be with the pure colors without any impurities. It will bring pleasure to people with bright and beautiful color.

5.6. Combination of human and animal: in expression of interest in life and longing for a better life, such as the rider, the scene of ox drags the cart and Mo Chung fights with tiger, unicorn appearance, etc[5].

\section{CONCLUSIONS}

The content and form of folk art is strongly influenced by folk activities and their own agreements. It becomes the carrier of the folk image[6]. Various images of Xiaoguo clay sculpture are carried with local culture, thoughts, with distinctive ethnic features and strong geographical characteristics. The shape, color and craft procedure of Xiaoguo clay sculpture are all loaded with folk art profile, which reflected the aesthetic view of the local people.

Folk art is not only popular in the cultural ecological environment of the society, but also profoundly embodies the spirit of folk culture as well as many features of it. Xiaoguo clay sculpture rooted in the soil of folk art, maintaining local character, which has shown from the aspects of style, shape, color and so on.

Lanling Xiaoguo Clay Sculpture has formed its own style with the accumulation of long-terms living experience and the painting strokes has its own unique features. It still retains the folk culture of the traditional implications. The reason why Xiaoguo clay sculpture gained its prestigious reputation is that the emphasis on tradition and development of folk culture, which maintains the emotional inheritance and stretches the cultural cohesion in the society.

\section{Acknowledgment}

The authors wish to give their sincere thanks to the editor and the anonymous referees for their valuable suggestions and helpful comments which improved the presentation of the paper.

\section{References}

[1] Wang Lianhai, The Toy Art of China [M]. Changsha, Hunan Province, Hunan Fine Arts Publishing House, 2006.

[2] Cangshan Chorgraphy Compilation and Editing Committee: Cangshan Chorgraphy [M]. Beijing, Zhonghua Book Company, 1998.

[3] Gu Hao, Tuoring, The Existence of Cangshan Xiaoguo Clay Sculpture[M], Beijing, China Light Industry Press, 2013.

[4] ZhengHannong, Zuo Ailian, Cangshan Xiaoguo Clay Toy [J], Folklore Studies, 3rd Edition, 1994.

[5] Changshan Historical Data Compilation Committee, Changshan Historical Data Digest[M], Jinan, Shandong Province, Map Publishing House of Shandong Province, 2003.

[6] Changshan County Party Committee, Cangshan Culture / Folk Customs [M], Jinan, Shandong Province, Shandong Publishing House of Literature and Art, 2010 